\title{
The Reform of Econometrics Teaching Model Based on MOOC Environment
}

\author{
Zheng Bingyun \\ School of management science and engineering \\ Anhui University of Finance and Economics \\ Bengbu, China \\ Email:engzh519@163.com
}

\begin{abstract}
Econometrics is a core course in the economic and management specialty. This paper discusses the main problems that are irrationality of courses' arrangement, ignorance of bringing up ability and practice appliance and irrationality of teaching methods. Blended teaching with MOOC is an innovative teaching methodology relying on the Internet. In order to improve the teaching effect and reach the goal of reform, we should have a deep understanding to the MOOC and MOOC optimization of econometrics teaching to improve teaching quality. At last the paper proposes some advice on the reform of econometrics teaching with pertinence.
\end{abstract}

Keywords-Econometrics; Teaching Model; software operation; MOOC

\section{INTRODUCTION}

"Econometrics" has set up for more than 20 years as a course in the economic and management specialty of some institutions in China. Its importance has gradually been recognized. In July 1998, the Ministry of Education Economics Education Advisory Committee discussed and determined that "econometrics" is one of the eight common core courses for each of the categories of institutions of higher learning economics professional disciplines of in China, it is an important indicator that economics education walks up to modernization and scientology [1]. In scientific research, papers published in "Economic Research", "China's industrial economy" and other important economic journal, more and more emphasis on qualitative analysis and quantitative studies combined, and extensive various econometric models are used Therefore, from the point of view of both teaching and research, the teaching of econometrics courses should be given adequate attention and improvement.

After years of effort, econometrics course construction has made some achievements. Fully understanding the role of this course, we sum up the teaching practice conscientiously, and feel that here are many problems needed to further study in the construction of econometrics courses. This paper summarizes some of the problems encountered in econometrics teaching process and some ideas, and tries to sort out these problems and make some recommendations, and provides reference for the econometrics teaching of the ordinary institutions of higher learning.

\section{THE MAIN PROBLEMS IN THE TEACHING OF ECONOMETRICS}

\section{A. Curriculum unreasonable}

First, it is unreasonable to plan the advanced and follow-up curriculum. Teachers teaching econometrics econometric in ordinary institutions of higher learning know that it is necessary to study calculus, probability theory, economic statistics, and other related knowledge as reserves. However, in the process of teaching, we find that because of unreasonable curriculum planning, students yet to learn the necessary courses in advance, the teaching of the course is difficult.

Second, the number of hour arrangement is not reasonable. Some universities have opened many courses to increase students' knowledge widely width, thus compress some of the hours of important lessons. For example, econometrics courses including learning software, arrangements for a total hour is 54 , in some universities, it is even only 36 hours. So it is difficult to arrange the teaching content to teachers.

\section{B. Attach importance to theory and method system, but make light of capacity-building and practical application}

Econometrics teaching attaches importance to complete theory and method system at all levels, but the practical application of these theoretical approaches is relatively weak. Econometric studies should include the establishment of the model, the estimated parameters, model testing and application of the model. The current teaching mainly focuses on parameter estimation and test theories and methods. But discuss is less on how to proceed from the economic problems modeled and how to apply the model. In the teaching of econometrics, the use of hands-on training software is still a weakest link, the students learn a lot of estimation and testing methods, but do not know how to use, or can't provide a reasonable explanation for the results of the calculation. So the actual ability of using econometric model to analyze and solve the economic problems of the actual ability need be further strengthened [2]. 


\section{Irrational Teaching methods}

\section{1) Multimedia teaching}

Because there are a large number of matrix to derive in the econometrics course, and it is difficult to show large matrix on the blackboard, so it is generally needful to use multimedia teaching methods. Multimedia teaching model has many advantages, including take full advantage of human resources, prompt teachers to constantly update their knowledge contents and the system, strengthen the case teaching, help teachers to quickly update the content of teaching, use fully modern teaching equipment, and reflect the students' dominant position in the teaching process. However, due to the reduction of the time of writing on the blackboard, if the teachers can't grasp of the plan of the classroom teaching, and arrange classroom time reasonably, it is easy to speed up the plan of teaching, and fill in teaching content to their students in a short period of time. This results in increasing the strength. So students can't understand the teaching content in a timely manner.

\section{2) Software teaching}

In the teaching of the course, we talk about the theory and method, and leave a few hours to study software, or simply do not talk about the software. The students do not know how to apply the software after finishing this course. On the choice of software, and some colleges and universities still use the TSP as an analytical tool, and some universities have chosen to function very comprehensive but requires some programming software, such as SAS, less lesson is obviously very difficult to obtain a satisfactory effectiveness of teaching.

\section{SUGGESTIONS FOR ECONOMETRICS TEACHING REFORM}

\section{A. To strengthen communication between instructors and teaching administration}

Academic administration take charge of all the curriculum management, and allocate the school resources of human resources, classroom and supplementary. Since it is impossible to have an in-depth understanding of each course in the curriculum management for teaching management department, reasonable phenomenon will emerge inevitably in the process of curriculum management. This requires the instructor and teaching management departments to communicate effectively.

"Econometrics" Economics and Management professional core curriculum, but it is also a practice teaching is closely linked to curriculum, teaching experience from our analysis of reasonable hours arrangements should be 72 hours. Teaching semester, in general, for economics and management professional best arrangements in junior semester statistical and quantitative economics can advance to the next semester sophomore. Then, the students have mastered the knowledge.

\section{B. To focus on the practical application}

For college undergraduate students (especially nonstatistical and quantitative economics profession), the main purpose of the study of econometrics In order to apply, explain the theory and methods to pay close attention to the reaction of the students, according to student the level of understanding to make adjustments for some of the more difficult mathematical deduction can be properly cut, pay attention to the theory of systematic and integrity, cultivate the ability of students to apply theory to solve practical problems.

(1) Take practice teaching and theory teaching in close contact. Econometrics courses, theoretical teaching and experimental teaching are the two components complement each other, and neither is dispensable, therefore, both reasonable convergence is essential. In teaching time arrangements, both should co-ordinate planning, in accordance with the progress of the teaching content to reasonable arrangements for the experimental teaching time, each chapter after the completion of the theoretical teaching, immediately experimental teaching, teachers combine Example lectures and presentations theoretical approaches software implementation arrange for students to complete assignments, instant on-site explanations and comments by the teacher, to help students deepen understanding of theoretical knowledge and grasp. For 18 weeks of 54 hours of theoretical teaching, under normal circumstances, two weeks to be completed by a doctrinal teaching of the important points, so every two weeks, arrange 2 hours of experimental teaching more appropriate timing in the two weeks last theory class after nine weeks a total of 18 hours. As a result, the test teaching and teaching the theory closely co-ordinated timing is conducive to student learning.

(2) Organize classroom case teaching. The so-called case teaching, is to provide for the theories and methods appropriate to the reality of background, so that students have the feeling, the actual problem to be solved through careful analysis, to enable students to appreciate the need for a theoretical and methodological and effectiveness in this process, and understanding of the theory and method. The problem is often the lack of case discussion teaching students misunderstand the nature of the course, can not tell the difference between econometrics and statistics, mathematics where, may produce fear emotions. With the depth of the course, students go through several case discussion, gradually spontaneously generate realistic economic issues of interesting, they will consciously try to use econometric models to analyze these problems. Case teaching for the teaching of the course can play a good effect of teaching highly motivated everyone's enthusiasm for learning and participation in case discussions. Of course, case teaching classroom teachers is a very challenging work, requires careful organization of the classroom teachers, arrangements and implementation. Case teaching as long as the appropriate organization, will surely be teaching econometrics effect has played a significant role in promoting and widely used.

\section{Arrangement course papers}

The contents of the application of econometric models "since the end of the taught, so that students with professional features and real economic hot issues, the use of econometric methods to write a course paper of not less than 5,000 words, to develop their use of econometric methods to analyze and solve practical problems. Students according to the given problem or optional subject, according to economic theory, collect relevant data, and then apply classroom learning method of analysis of the socio-economic reality, the completion of a mini-course papers. The course paper, to a 
certain extent, can deepen students' understanding of the knowledge of the master and encourage them to pay more attention to the reality of the socio-economic problems. Many students course papers, as amended, developed into a high quality thesis research capacity has improved significantly. In addition, some of the teachers featured course papers, some students in their methods, main ideas, learn from, and there are insufficient to explain the other students to discuss and express their views, comments and summary later teachers, thereby enhancing the student learning initiative and participation, the ability to analyze and solve problems also increased. My school teaching econometrics courses, the organization of courses paper nearly 10 years of practice, and have achieved good teaching results.

Of course, in the implementation process, due to the imperfect system of students' knowledge, it will expose some common problems. First, the majority of students lack of understanding to the basic paradigm of economics paper a, and do not know the paper should contain the logical relationship between the elements as well as elements of the course work is not complete, or the advice given analysis is not logical necessity correlation; or improper topics and difficult to grasp, did not meet the purpose of the writing course papers. This requires teachers to make reasonable arrangements and guidance. Arranged to the course papers, students can not pay a first draft, teachers end given the results, should the existing problems and the corresponding recommendations timely feedback to the students by the students to be modified accordingly. In addition, as described above, the teachers featured some of the best course papers to learn together how to theoretical analysis of selected issues, how to collect the appropriate data for empirical research papers framework and other aspects of how to build, step by step to improve the students to write The quality paper basic literacy [3].

\section{Emphasis on software operation}

The econometric application without the use of software, if you do not know how the operation of the measurement software, it can not be the theory or model used in practice. Some institutions forced by faculty or other reasons, for the measurement of software application learning not given full attention, and usually come up with a few lessons taught by teachers demonstrate a metrology software operation, such as the use of Eviews software. In this learning process, students can only passively accept knowledge but can not play its initiative. And if the students are able to personally operate the software to build an econometric model empirical analysis, even if it is a fairly simple linear regression model will bring a greater sense of accomplishment to the students, recognizing econometric theory and measurement software phase combined with the use of the benefits, so as to develop students' strong interest in study of econometrics.

Econometric modeling applications such for EVIEWS, SPSS, SAS, are widely used in the econometric analysis applications. Software processing is consistent with the principle of the method, so we just understand and are proficient in one kind of software. In econometrics, EViews is our recommended software, which can solve the econometric all the contents of operational problems, and the interface visualization. If time is tight, on the one hand, to stimulate students can do a demo of some software to provide students with a learning platform, to facilitate the after-school students are interested in learning if sufficient time can be a more detailed description of the various menus and functions of the software interest in learning, it also reinforces the learning.

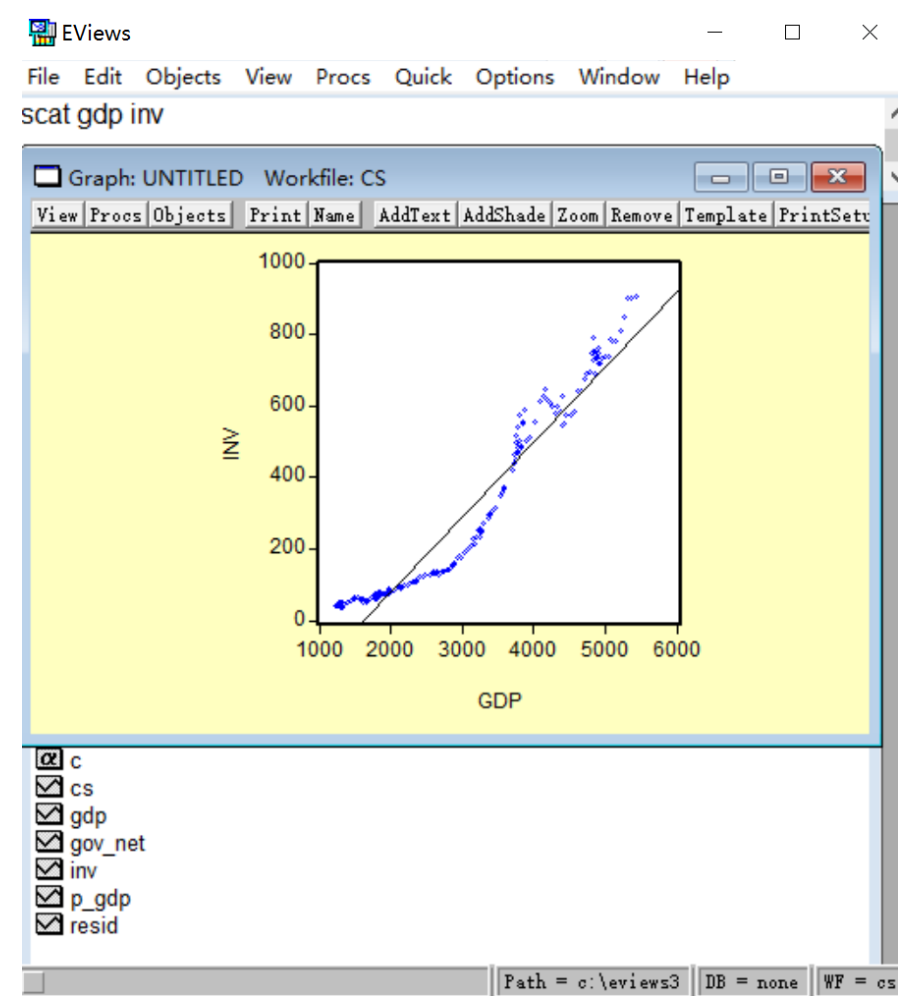

Fig. 1 A operation to scat of Eviews software

\section{E. Interactive teaching based MOOC environment}

The concept of MOOC, the abbreviation of Massive Open Online Courses, was first put forward by Dave Cormier, professor of Canadian Edward Prince Island University, and Bryan Alexander, the senior researcher of National Research Institute of Human Education in Canada. In 2012, the MOOC was introduced to the Stanford University, the California University, the Michigan University and the Princeton University, etc. in America. In recent years, the construction and researches of MOOC have become the hot issue home and abroad along with the rapid development in the Internet technology. MOOC brings about the revolution of the education mode in the digital and information age with its outstanding teaching resources. MOOC is a kind of new teaching mode of collection of internet, multimedia and mobile terminal equipment and other high-tech, with openness, sharing the general characteristics and typical interactive and high efficiency of the Internet technology, its essence is the Internet and information equipment as the main basis, so as to realize the innovation of the traditional teaching concept, teaching mode and teaching thinking, plays a vital role in promoting the development of quality education[4-5]. 
On the one hand, with the aid of MOOC, the advanced concepts at home and abroad can be introduced [6]. MOOC belongs to the online course learning model, which is not limited by time and space. Therefore, in the process of reforming the teaching model, we can make full use of the characteristics of $\mathrm{Mu} \mathrm{Mu}$ class, draw on and absorb the advanced concepts at home and abroad, and optimize the teaching methods of economics.

On the other hand, it can realize the diversification effect of classroom teaching mode. Based on various teaching method, MOOC is supplemented as a new way of teaching. When teaching Econometrics related theoretical knowledge, teachers first explain to the students systematically, and then use MOOC, listen to experts, teachers on the part of the content of the explanation. On this basis, through comparison and analysis of different teachers to explain, so that students master the knowledge more comprehensive and rich.

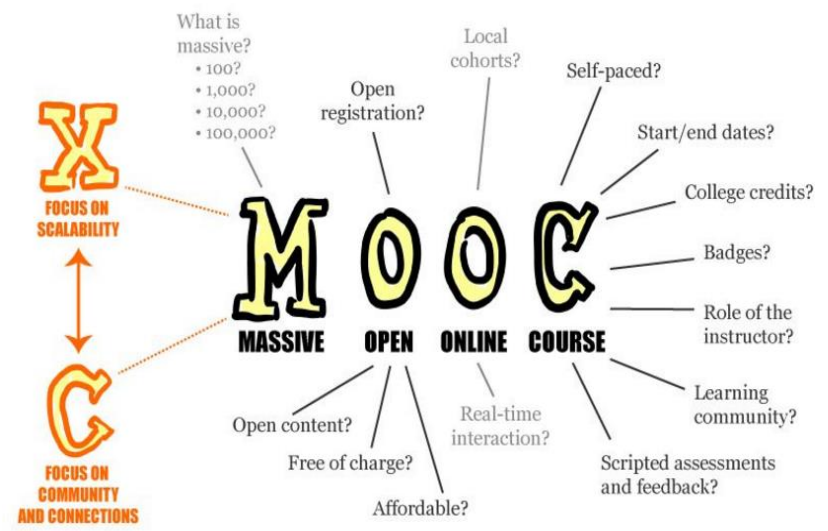

Fig. 2 MOOC teacher model

\section{CONCLUSION}

The choice of materials and construction of the platform of network resources is also a measurement of the need to seriously think about the reform of the economics teaching. In short, undergraduate econometrics "is a comprehensive course in the teaching process, teachers, how can we do to impart basic knowledge of books completed in the teaching process, but also to train students utilize this tool to analyze and the ability to solve practical problems, it is worthy of our common thinking. I hope the exploratory analysis can play the role of teachers engaged in the teaching of econometrics, to jointly promote the teaching reform of econometrics. I believe that as long as we can properly handle the key points in the teaching process, the econometrics teaching reform based on MOOC can and must be successful.

\section{REFERENCES}

[1] G. Eason, B. Noble, and I.N. Sneddon, "On certain integrals of Zinai Li. Advance Econometrics[M]. Beijing: Peking University Press, 2000.

[2] Liping Wang, Jian Wang. Research on Econometrics Experimental Teaching Reform $[\mathrm{J}]$. Jounal of ShanXi Financeand Economics University in Chinese, 2006 (4):56-58.

[3] Wong Siu Ping, SI Shu Yao. Capacity-Building In The Teaching Of Econometrics[J]. Educational Research in Chinese, 2012 (7):110-114.

[4] Wang Bing. The College English Teaching Reform Based on MOOC[J]. English Language Teaching in Chinese, $2017,10(2): 19-22$.

[5] Zhang Tongguang.Reform and Innovation of Teaching Mode in Universities Under the Background of MOOC. [J]. Journal of Jixi University in Chinese,2016(12):18-21.

[6] Chen Wenzhen.An Applied Research on Blended Teaching of "Ideology and Morality Cultivation and Legal Rudiment"and MOOC[J]. Journal of Xiangnan University in Chinese,2017(1):93-96. 